\title{
Cellulose nanofibrils as filler for adhesives: effect on specific fracture energy of solid wood-adhesive bonds
}

\author{
Stefan Veigel • Ulrich Müller • Jozef Keckes • \\ Michael Obersriebnig • Wolfgang Gindl-Altmutter
}

Received: 15 February 2011/Accepted: 5 July 2011/Published online: 15 July 2011

(C) Springer Science+Business Media B.V. 2011

\begin{abstract}
Cellulose nanofibrils were prepared by mechanical fibrillation of never-dried beech pulp and bacterial cellulose. To facilitate the separation of individual fibrils, one part of the wood pulp was surface-carboxylated by a catalytic oxidation using (2,2,6,6-tetramethylpiperidin-1-yl)oxyl (TEMPO) as a catalyst. After fibrillation by a high pressure homogenizer, the obtained aqueous fibril dispersions were directly mixed with different urea-formaldehyde(UF)-adhesives. To investigate the effect of added cellulose filler on the fracture mechanical properties of wood adhesive bonds, double cantilever beam specimens were prepared from spruce wood. While the highest fracture energy values were observed for UFbonds filled with untreated nanofibrils prepared from
\end{abstract}

S. Veigel $(\bowtie) \cdot$ M. Obersriebnig · W. Gindl-Altmutter Department of Material Sciences and Process Engineering, Institute of Wood Science and Technology, BOKU-University of Natural Resources and Life Sciences, Konrad Lorenz Straße 24, 3430 Tulln a.d. Donau, Austria

e-mail: stefan.veigel@ boku.ac.at

U. Müller

Wood K plus-Competence Centre for Wood Composites and Wood Chemistry, St.-Peter-Straße 25,

4021 Linz, Austria

\section{J. Keckes}

Erich Schmid Institute of Materials Science, Austrian Academy of Sciences and Institute of Metal Physics, University of Leoben, Jahnstraße 12,

8700 Leoben, Austria wood pulp, bonds filled with TEMPO-oxidized fibrils showed less satisfying performance. It is proposed that UF-adhesive bonds can be significantly toughened by the addition of only small amounts of cellulose nanofibrils. Thereby, the optimum filler content is largely depending on the adhesive and type of cellulose filler used.

Keywords Cellulose - Nanofibrils · Filler . Adhesive · Fracture energy

\section{Introduction}

Bonding of solid wood is a key issue in the manufacturing of numerous wood products. Especially regarding applications in the structural field, mechanical performance of wood-adhesive bonds is of fundamental importance. Apart from other influencing factors like adherend material, geometric design of the bond line and its loading conditions, the adhesive properties significantly impact the strength of an adhesive bond (Habenicht 2002). In this regard, the addition of fibrous fillers to the liquid adhesive is one potential opportunity of increasing strength. Organic flours that are commonly applied as fillers for urea-formaldehyde-(UF)-adhesives primarily improve the processing characteristics of the adhesive mixture, although they may contribute to bonding strength by agglutination of starch during hot pressing (Dunky and Niemz 2002). If fibers are added 
to the adhesive, the cured adhesive bond line may be considered as a fiber-reinforced polymer. From composite science it is known, that the smaller the fiber diameter, the higher the attainable strength will be (Griffith 1920). Consequently, there were several attempts in the past to improve the mechanical performance of adhesive joints by reinforcing the adhesive with nanoparticles (Zhang et al. 2008; Ahmad et al. 2010; May et al. 2010; Khoee and Hassani 2010) or nanofibers (Hsiao et al. 2003; Ureña et al. 2008; Khalili et al. 2008, 2009; Prolongo et al. 2009, 2010; Yoon et al. 2010) from high-strength materials.

Unlike in the past, where predominantly glass fibers, polymeric fibers and carbon fibers were used for adhesive reinforcement, nanofibrils from cellulose were used in this study. This abundant biopolymer offers outstanding mechanical properties especially when it is applied as a nano-scale material. The crystalline part of the cellulose has an estimated strength of up to $10 \mathrm{GPa}$ (Zimmermann et al. 2004) and an elastic modulus in the range of $138 \mathrm{GPa}$ (Sakurada et al. 1962; Nishino et al. 1995). Although the values determined for cellulose nanofibrils (CNF) are lower due to paracrystalline regions and material degradation during processing, fibrils based on cellulose can be considered as fairly competitive to synthetic fiber materials. This is especially true when the low density of cellulose is taken into consideration.

Two recently published articles address for the first time the application of CNF for wood-adhesive reinforcement. In a study performed by LópezSuevos et al. (2010), the suitability of CNF for the preparation of polyvinylacetate-(PVAc)-bond lines with improved temperature resistance was investigated. For this purpose, lap shear specimens according to EN 205 with a cellulose content of up to $3 \mathrm{wt} \%$ were prepared and tested to failure. Although the cellulose-reinforced bond lines generally performed worse in dry and wet conditions, the bonds showed superior heat resistance.

Richter et al. (2009) tried to improve the rheological behavior and bonding properties of two different wood-adhesives (i.e. one component polyurethane(1C-PUR)-adhesive and water-based polyvinyl acetate latex-(PVAc)-adhesive) by adding CNF. Among other things, lap-shear testing according to EN 302-1 as well as block shear testing was performed. Cellulose content of the adhesive mixtures was increased up to
$10 \mathrm{wt} \%$ for 1C-PUR and $1.33 \mathrm{wt} \%$ for the PVAcadhesive. PVAc-adhesive films with cellulose reinforcement showed a direct correlation between the $\mathrm{CNF}$-content of the adhesive formulation and the stiffness and strength properties of corresponding films. In spite of this, no significant and consistent improvement of bond line performance compared to non-reinforced reference products was achieved neither for PUR nor for PVAc. According to Richter et al. (2009), a quality controlled fibril morphology, a homogeneous dispersion into the adhesive as well as a comparable polarity of fibrils and adhesive polymers are critical parameters affecting the mechanical performance of the adhesive bond.

In contrast to the studies mentioned above, two different UF-adhesives were used in the present study. These resins generally show a much more brittle material behavior than PVAc- and 1C-PURadhesives. Therefore, UF-adhesives tend to create micro-cracks that limit the mechanical performance of UF-bonds. Own investigations revealed that longitudinal shear strength of UF-bonds can be improved up to $30 \%$ by adding about $5 \mathrm{wt} \%$ of $\mathrm{CNF}$ to the liquid adhesive (Eichhorn et al. 2009). Since apart from strength, also strain to failure was found to be considerably higher, it was concluded that the UFadhesive was possibly toughened by the addition of CNF. Consequently it is the aim of the present study to evaluate a potential effect of a CNF-addition on the specific fracture energy of UF-adhesive bonds.

\section{Materials and methods}

\section{Preparation and characterization of CNF}

For the preparation of CNF-dispersions, never dried dissolving grade beech pulp (Lenzing AG, Lenzing, Austria) with an initial solid content of about $50 \%$ was used as a starting material. One half of the pulp was directly used for high pressure homogenization, i.e. without further pretreatment (P1), while the other half was chemically modified by carboxylation (P2) with the aim of facilitating the separation of individual cellulose fibrils during the following homogenization process. The P2-dispersion was prepared by direct surface carboxylation using (2,2,6,6-tetramethylpiperidin-1-yl)oxyl (TEMPO) as a catalyst and sodium chlorite as a primary oxidant under 
neutral conditions as described by Saito et al. (2009). Apart from wood pulp, also bacterial cellulose (BC) was used for CNF preparation. The celluloses (P1, P2 and $\mathrm{BC}$ ) were suspended in distilled water and fibrillated by 20 passes through a high pressure laboratory homogenizer (APV 1000, APV Manufacturing Sp. z o.o., Bydgoszcz, Poland) with a pressure of up to 850 bar. After homogenization, the dispersions were air dried at $60{ }^{\circ} \mathrm{C}$ to increase the cellulose content to about $4 \%$ by weight.

To evaluate the degree of fibrillation, dried cellulose fibrils were sputter-coated with $7.5 \mathrm{~nm}$ of platinum and observed by a field emission scanning electron microscope (FE-SEM, Nova NanoSEM 230, Hillsboro, USA). In order to verify potential effects of TEMPO modification on the structure of cellulose fibrils, wide-angle X-ray diffraction (WAXD) was performed with dried cellulose films using a Nanostar (Bruker AXS) system connected to a rotating anode generator with $\mathrm{Cu}$ target. The system is equipped with crossed Göbel mirrors, a pinhole system for a primary collimation with a beam diameter of $100 \mu \mathrm{m}$ and a two dimensional (2D) wire detector (Hi-Star). The 2D detector images were acquired and evaluated using Fit2D software.

To investigate a potential effect of cellulose addition on the adhesive's cure rate, the $\mathrm{pH}$ value and buffer capacity of the cellulose dispersions were determined using a microprocessor-pH-meter (CG 840, Schott Geräte GmbH, Hofheim a. Ts., Germany) equipped with a $\mathrm{pH} /$ temperature combination electrode (N 1042 A). The buffer capacity was determined by titrating $10 \mathrm{~mL}$ of the cellulose dispersion (cellulose content $1 \%$ by weight) with $0.1 \mathrm{M}$ sulphuric acid until a $\mathrm{pH}$ value of 2 was reached. Average buffer capacity values were calculated for the $\mathrm{pH}$ range from 2 to 7 by dividing the amount of acid consumed by the resulting change in $\mathrm{pH}$.

Preparation of double cantilever beam-(DCB)specimens

For fracture energy testing, the simplified flat double cantilever beam-(DCB)-specimen geometry as described by Gagliano and Frazier (2001) was applied. The specimen consists of two wood adherends with a $3^{\circ}$ longitudinal grain angle. Since the grain of both adherends converges to a V-shape at the bond line (Fig. 1), wood failure can be reduced to a minimum. Flawless spruce wood (Picea abies Karst.) with a density of $450 \pm 18 \mathrm{~kg} / \mathrm{m}^{3}$ was bonded with two UF-adhesives, namely a non-structural powderadhesive for solid wood bonding (UF-1, W-Leim Spezial, Dynea Austria GmbH, Krems, Austria) and a low viscosity UF-adhesive used in particle board production (UF-2, Prefere 10F101, Dynea Austria $\mathrm{GmbH}$, Krems, Austria). According to the manufacturer's instructions, UF-1 was mixed with water in a weight ratio of 5:3. For the preparation of cellulosefilled adhesives, the powder was mixed with the fibrillated cellulose dispersions instead of water. To achieve proper dispersion of cellulose fibrils within the adhesive, mixing was performed with a hand blender for $3 \mathrm{~min}$. It is worth mentioning that in case of P2, small cellulose particles could be visually observed even after mixing with the adhesive. Adhesive mixtures with a cellulose content of $0.5,1.0,1.5$ and $2.0 \%$ per unit weight of cured UF were prepared with both adhesives. A spreading quantity of $250 \mathrm{~g} / \mathrm{m}^{2}$ of solid resin was used for all adhesive assemblies. The specimens bonded with UF-1 were cured at room temperature using a pressure of $0.8 \mathrm{MPa}$. As usual in
Fig. 1 Geometry of flat double cantilever beam(DCB)-specimens used for fracture energy determination of wood adhesive joints. All dimensions in $\mathrm{mm}$
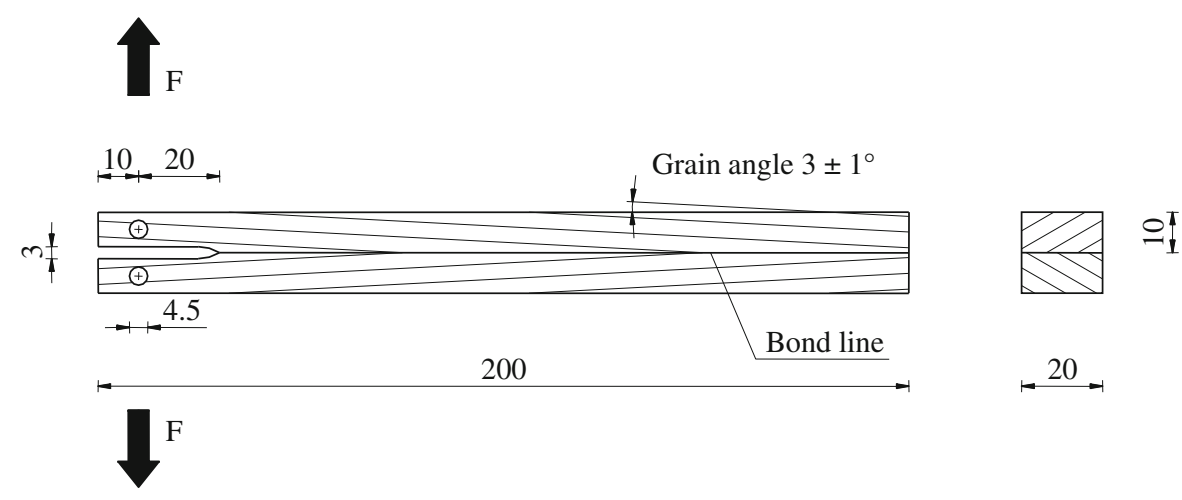
the production of particle boards, ammonium sulphate ( $3 \%$ by unit weight of cured UF) was used as a hardener for UF-2. To avoid a further decrease in solid content, the powdery hardener was dissolved in the respective cellulose dispersion which was thereafter added to the adhesive. The composition of the individual adhesive mixtures and the resulting solid contents are summarized in Table 1 . In the case of UF-2, apart from cellulose, a large amount of water is added to the adhesive system. Since it was assumed that this results in a decelerated adhesive cure, the gel times of all UF-2 adhesive mixtures were determined. Therefore, about $2 \mathrm{~mL}$ of the liquid adhesive were poured into a test tube and immersed in a boiling water bath. The time span from immersion until complete gelation of the adhesive represents the gel time. Adhesive joints prepared with UF-2 were cured at a temperature of $160{ }^{\circ} \mathrm{C}$ with a pressure of $0.5 \mathrm{MPa}$. Pressing time was $480 \mathrm{~min}$ for UF-1 and $15 \mathrm{~min}$ for UF-2. Under these conditions, complete curing can be assumed for both adhesive systems. The cured adhesive assemblies were cut to a final size of $200 \times 20 \times 20 \mathrm{~mm}^{3}$. For crack initiation, a
$30 \mathrm{~mm}$ long ogival shaped kerf was cut at one end of each specimen. Two holes were drilled to attach the test grips. All specimens were stored at $20{ }^{\circ} \mathrm{C}$ and $65 \%$ relative humidity until equilibrium moisture content was reached.

Mechanical testing

Fracture testing was performed on a Zwick/Roell Z100 universal testing machine equipped with a $2.5 \mathrm{kN}$ load cell. The DCB-specimens were initially loaded with a speed of $1 \mathrm{~mm} / \mathrm{min}$. After a 50\% drop in load, testing speed was increased steadily to a value of $10 \mathrm{~mm} / \mathrm{min}$. The specimens were tested until complete separation of the two parts and the load-displacement curve was recorded. Specific fracture energy $\left(\mathrm{J} / \mathrm{m}^{2}\right)$ was calculated by relating the total fracture energy obtained by integration of the load-displacement curve to the bonding surface area. All specimens with a wood failure greater than $10 \%$ were dropped out of the analysis. For the individual groups of specimens, mean values were calculated and compared by one-way analysis of variance (ANOVA, $p \leq 0.05$ ).

Table 1 Composition and gel times of adhesive mixtures

\begin{tabular}{|c|c|c|c|c|c|c|}
\hline \multirow{2}{*}{$\begin{array}{l}\text { Adhesive } \\
\text { mixture }\end{array}$} & \multirow{2}{*}{$\begin{array}{l}\text { Cellulose content } \\
\text { (wt\% of cured UF) }\end{array}$} & \multicolumn{3}{|c|}{ Quantity (g/100 g adhesive mixture) } & \multirow{2}{*}{$\begin{array}{l}\text { Total solid } \\
\text { content }(\%)\end{array}$} & \multirow{2}{*}{$\begin{array}{l}\text { Gel } \\
\text { time (s) }\end{array}$} \\
\hline & & Cellulose & Water & Hardener & & \\
\hline UF-1 & 0 & 0.00 & 37.50 & - & 62.5 & - \\
\hline \multirow[t]{4}{*}{$\mathrm{UF}-1+\mathrm{P} 1 / \mathrm{P} 2 / \mathrm{BC}$} & 0.5 & 0.31 & 37.19 & - & 62.8 & - \\
\hline & 1.0 & 0.63 & 36.88 & & 63.1 & \\
\hline & 1.5 & 0.94 & 36.56 & & 63.4 & \\
\hline & 2.0 & 1.25 & 36.25 & & 63.8 & \\
\hline UF-2 & 0 & 0.00 & 33.34 & 1.94 & 66.7 & 55 \\
\hline \multirow[t]{4}{*}{$\mathrm{UF}-2+\mathrm{P} 1$} & 0.5 & 0.30 & 38.16 & 1.79 & 61.8 & 59 \\
\hline & 1.0 & 0.56 & 42.28 & 1.66 & 57.7 & 65 \\
\hline & 1.5 & 0.78 & 45.86 & 1.55 & 54.1 & 70 \\
\hline & 2.0 & 0.97 & 49.00 & 1.46 & 51.0 & 73 \\
\hline \multirow[t]{4}{*}{$\mathrm{UF}-2+\mathrm{P} 2$} & 0.5 & 0.30 & 38.16 & 1.79 & 61.8 & 57 \\
\hline & 1.0 & 0.55 & 42.29 & 1.66 & 57.7 & 60 \\
\hline & 1.5 & 0.78 & 45.87 & 1.55 & 54.1 & 65 \\
\hline & 2.0 & 0.97 & 49.00 & 1.46 & 51.0 & 68 \\
\hline \multirow[t]{4}{*}{$\mathrm{UF}-2+\mathrm{BC}$} & 0.5 & 0.30 & 38.48 & 1.78 & 61.5 & 60 \\
\hline & 1.0 & 0.55 & 42.84 & 1.65 & 57.2 & 67 \\
\hline & 1.5 & 0.77 & 46.60 & 1.53 & 53.4 & 73 \\
\hline & 2.0 & 0.96 & 49.86 & 1.43 & 50.1 & 78 \\
\hline
\end{tabular}

$U F-1, U F-2$ pure adhesives, Cellulose nanofibrils prepared from $P 1$ untreated pulp, $P 2$ TEMPO-oxidized pulp and $B C$ bacterial cellulose 
Characterization of cured bond lines

The cured bond lines were characterized using nanoindentation and optical microscopy. Small cubes with dimensions of $2 \times 2 \times 1 \mathrm{~mm}^{3}$ (width $\times$ thickness $\times$ length) containing the bond line in the center, were cut out of the DCB-specimens that had not been tested. The cubes were infiltrated with embedding medium (Agar Low Viscosity Resin R1078, Agar Scientific Ltd, Stansted, England) which was cured in an oven at $60{ }^{\circ} \mathrm{C}$ for $24 \mathrm{~h}$. The cured resin blocks were cut to a size of $2 \times 2 \times 2 \mathrm{~mm}^{3}$ (width $\times$ thickness $\times$ length) and a smooth surface was prepared by an ultramicrotome (Leica Ultracut R, Leica Microsystems, Wetzlar, Germany). The specimens were used for incident light microscopy (Axioplan 2 imaging, Carl Zeiss Microimaging $\mathrm{GmbH}$, Jena, Germany) and subsequently for nanoindentation.

The nanoindentation measurements were performed on a Hysitron TI-900 TriboIndenter equipped with a Berkovich tip. Four specimens were tested for each adhesive type (two specimens with pure adhesive bond lines and two bond lines filled with $2 \mathrm{wt} \%$ of P1). Indentation was performed in load-controlled mode using a pre-force of $2 \mu \mathrm{N}$. A 3-phase load profile was applied consisting of a loading phase where a load of $500 \mu \mathrm{N}$ was applied within $1 \mathrm{~s}$, a constant load phase with a duration of $20 \mathrm{~s}$ and an unloading phase lasting $1 \mathrm{~s}$. For each indent, a loaddepth curve was recorded and used to calculate the total work of indentation $\left(W_{t o t}\right)$ which can be further divided into an elastic $\left(W_{e}\right)$ and plastic $\left(W_{p}\right)$ part. The ratio of $W_{e} / W_{p}$ may be used to estimate the brittleness of the adhesive bond line. Indentation hardness was calculated by dividing the peak load by the contact area at the end of the constant load phase. As described by Konnerth et al. (2006), the reduced elastic modulus $\left(E_{r}\right)$ was calculated from the initial slope of the unloading curve and indentation creep
$\left(C_{I T}\right)$ was defined as the relative change of the indentation depth while the applied load is held constant.

\section{Results and discussion}

Characterization of cellulose nanofibrils

After high-pressure homogenization, differences in the optical appearance of cellulose fibril suspensions were observed. Unlike the unmodified P1- and BCdispersions, which were opaque, the TEMPO-treated P2-dispersion was optically transparent and showed a considerably higher viscosity at equal cellulose content. Since the viscosity further increased when water was removed from the suspension by drying, the P2-dispersion behaved almost like a solid when dried to a cellulose content of $4 \%$. At this content, the P2-dispersion took up the form of a gelatinous granulate with particles of different size, whereas the P1 and BC suspensions, respectively, were still liquid, though highly viscous.

FE-SEM microscopy confirmed differences in the structure of TEMPO-treated and untreated fibrils. As shown in Fig. 2, the untreated P1- and BC-nanofibrils form a loose fibril network after vacuum drying of the corresponding dispersions. In strong contrast, the TEMPO-treated P2-fibrils agglomerate to a very compact film when dried. This may be due to the fact that the introduction of carboxylate groups during the TEMPO-mediated oxidation causes significant changes in the surface properties of cellulose fibrils. Measurement of fibril diameters from the FESEM images revealed smaller fibrils for P2 compared to $\mathrm{P} 1$ and $\mathrm{BC}$, respectively. The mean fibril diameters were $61 \pm 21 \mathrm{~nm} \quad(\mathrm{P} 2), \quad 96 \pm 48 \mathrm{~nm} \quad(\mathrm{P} 1)$ and $109 \pm 56 \mathrm{~nm}(\mathrm{BC})$ whereas 50-60 fibrils have been measured for each cellulose material. The fibril
Fig. 2 FE-SEM

micrographs of cellulose nanofibrils prepared by high pressure homogenization of $B C$ bacterial cellulose and $P 1$ untreated beech pulp as well as $P 2$ TEMPOoxidized pulp
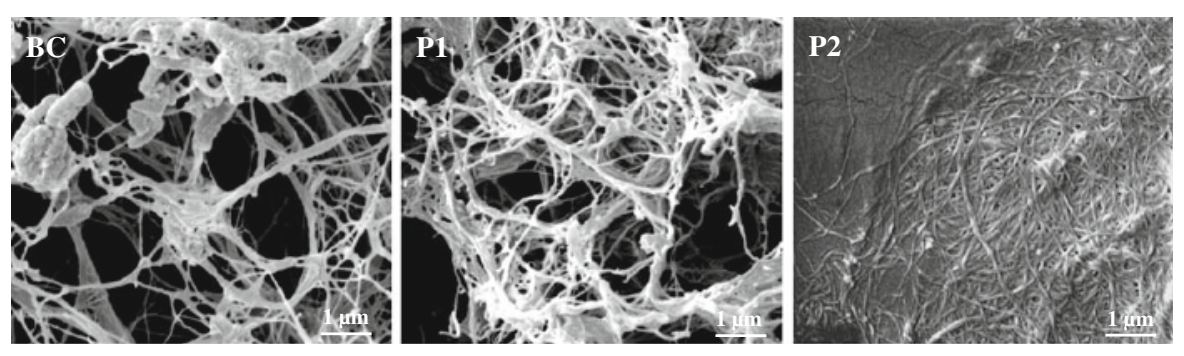
diameters obtained in this study seem rather high when compared to the results of previous studies (Saito et al. 2006, 2009; Iwamoto et al. 2010). This is probably because the fibril dispersions were used directly after homogenization without separating larger aggregates by centrifugation. Also, an additional sonication step might have further decreased the fibril size.

Since TEMPO-treatment seemed to have affected the fibril structure as indicated by FE-SEM images (Fig. 2), WAXD measurements were performed in order to reveal possible changes in their crystalline structure. Contrary to a previous study (Saito et al. 2009) where quite similar X-ray diffraction patterns were found for both untreated kraft pulp and TEMPOoxidized pulp, the WAXD-images of native (P1) and TEMPO-treated (P2) cellulose obtained in the present study differ considerably (Fig. 3). All celluloses investigated showed peak scattering intensities typical of cellulose I (Borysiak and Garbarczyk 2003). While both, P1 and BC are highly crystalline, TEMPOtreatment seems to have significantly reduced the crystallinity of $\mathrm{P} 2$. This is particularly obvious when a simple crystallinity index $\mathrm{c}$ is calculated from the scattering intensity $I_{c}$ of the cellulose 200 reflection at an angle of $22.7^{\circ}$ and the intensity $I_{\text {ref }}$ measured at an angle of $33^{\circ}$, where hardly any crystalline scattering was observed (Eq. 1).
$c=\left(I_{c}-I_{r e f}\right) / I_{c}$.

The crystallinity index $c$ is highest for BC with 0.98 and P1 with 0.94 and significantly reduced for P2 with 0.84 . In addition, it seems that not only the overall crystallinity of the cellulose fibrils was affected by TEMPO-modification, but also the average crystallite width. An assessment of the width of the cellulose 200 reflection peak at half the maximum intensity (full width at half maximum) for P1 and P2 shows a significant peak broadening in P2-cellulose. Since according to the Scherrer formula (Scherrer 1918) the peak width is inversely proportional to the crystallite size, this indicates a reduction of the width of cellulose crystallites after TEMPO-treatment.

Regarding their acid/base properties the three cellulose dispersions did not differ significantly. The initial $\mathrm{pH}$ values determined for $\mathrm{P} 1, \mathrm{P} 2$ and $\mathrm{BC}$ were $7.11,7.43$ and 7.02 , respectively. The average buffer capacities were found to be $4.93,6.75$ and $5.60 \mathrm{mmol} / \mathrm{L}$ for the $\mathrm{pH}$ range from 2 to 7 . Since the drop in $\mathrm{pH}$ caused by the addition of the acidic hardener by far compensates such low buffer capacities, the effect on adhesive's cure can be neglected. The increase of gel times with increasing cellulose content (Table 1) is therefore predominantly attributed to the lower solid contents of CNF-filled UF-2 adhesive mixtures.

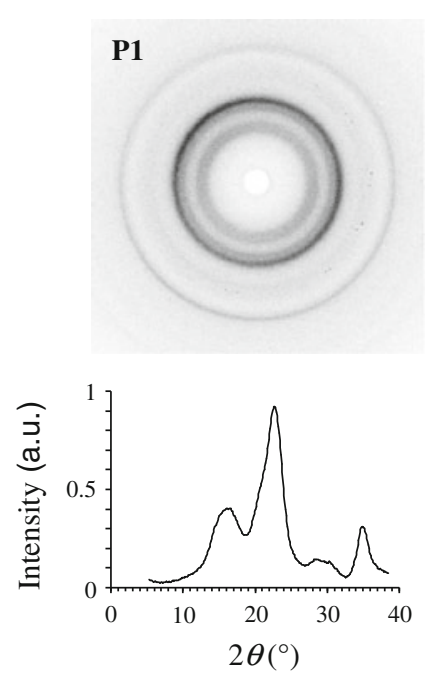

Fig. 3 X-ray diffraction patterns of cellulose films prepared by air drying of cellulose fibril dispersions ( $P 1$ untreated pulp, $P 2$ TEMPO-oxidized pulp, $B C$ bacterial cellulose). Intensity
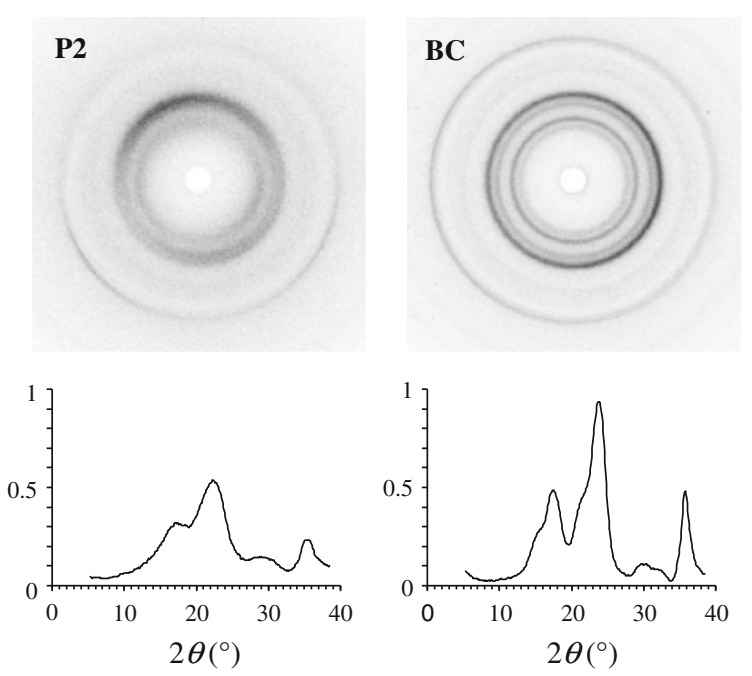

peaks are less pronounced for $P 2$, indicating that the TEMPOmediated oxidation caused a reduction in the degree of cellulose crystallinity 
Characterization of cured adhesive bond lines

An analysis using incident light microscopy (Fig. 4) revealed that for UF-1, bond line thickness clearly increased due to the addition of P1. This effect is primarily attributed to the high viscosity of the filled adhesive. Although the increase in viscosity was not quantified, the markedly higher viscosity of UF$1+\mathrm{P} 1$ and $\mathrm{BC}$ was clearly visually recognizable. In contrast, UF-1 + P2 showed almost the same viscosity and bond line thickness than pure UF-1. As mentioned earlier, visible particles of $\mathrm{P} 2$ remained after mixing. Due to the strong agglomeration tendency of $\mathrm{P} 2$ it was obviously not possible to achieve a uniform distribution of individual fibrils in the adhesive.
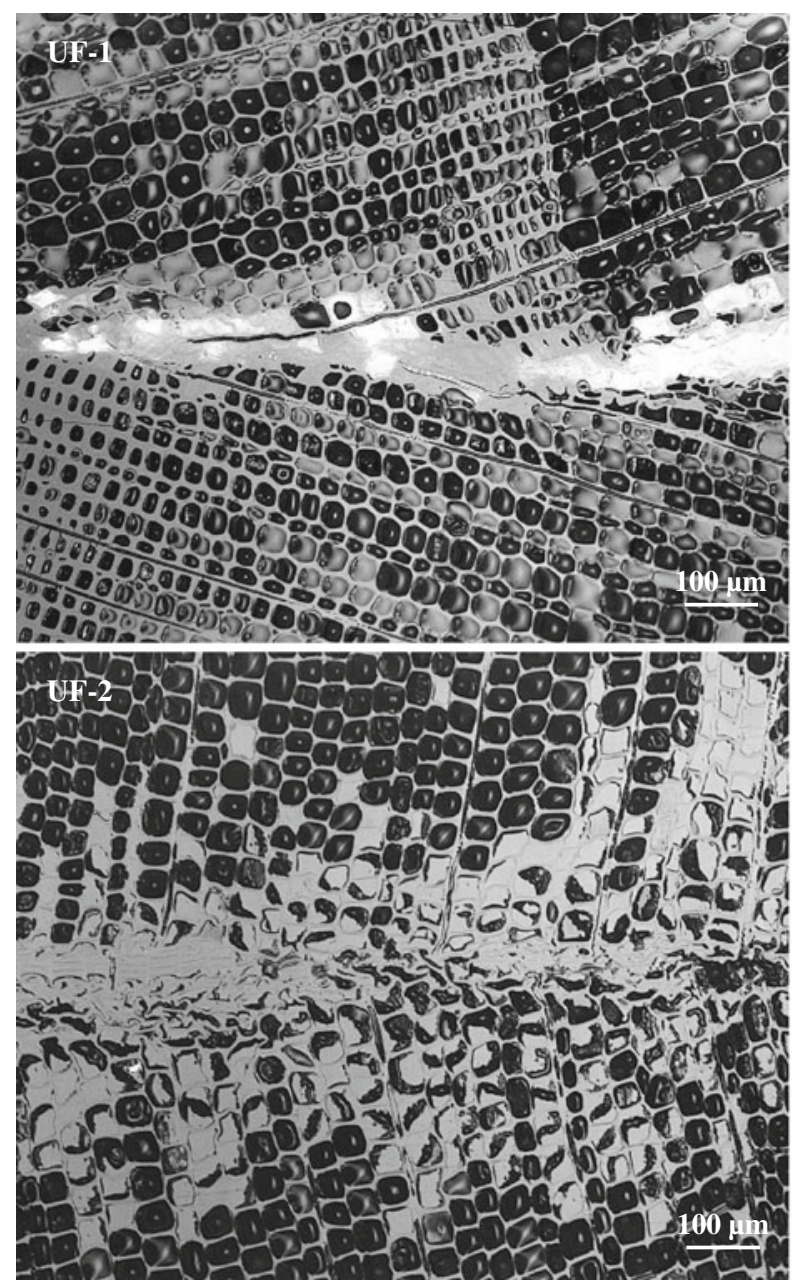

Fig. 4 Optical micrographs of urea-formaldehyde- $(U F)$ bond lines. Two different adhesives were applied, once without any additional filler (UF-1 and $U F-2)$ and once filled with $2 \mathrm{wt} \%$
In the case of UF-2, bond lines were generally thinner and bond line thickness did not increase substantially for the cellulose filled adhesives. The low thickness can be explained by the much lower viscosity of pure UF-2 compared to UF-1. While for UF-1 the total solid content remains roughly the same after cellulose addition, this is not true for UF-2. Since in case of the latter the solid content is reduced by the addition of extra water from the cellulose dispersion, viscosity increase is less pronounced than for UF-1. Therefore a considerable amount of both pure and cellulose filled UF-2 was squeezed out during pressing. As evident from Fig. 4, the P1-filler markedly reduced penetration of UF-2 into the cellular wood cavities. Although only slightly higher

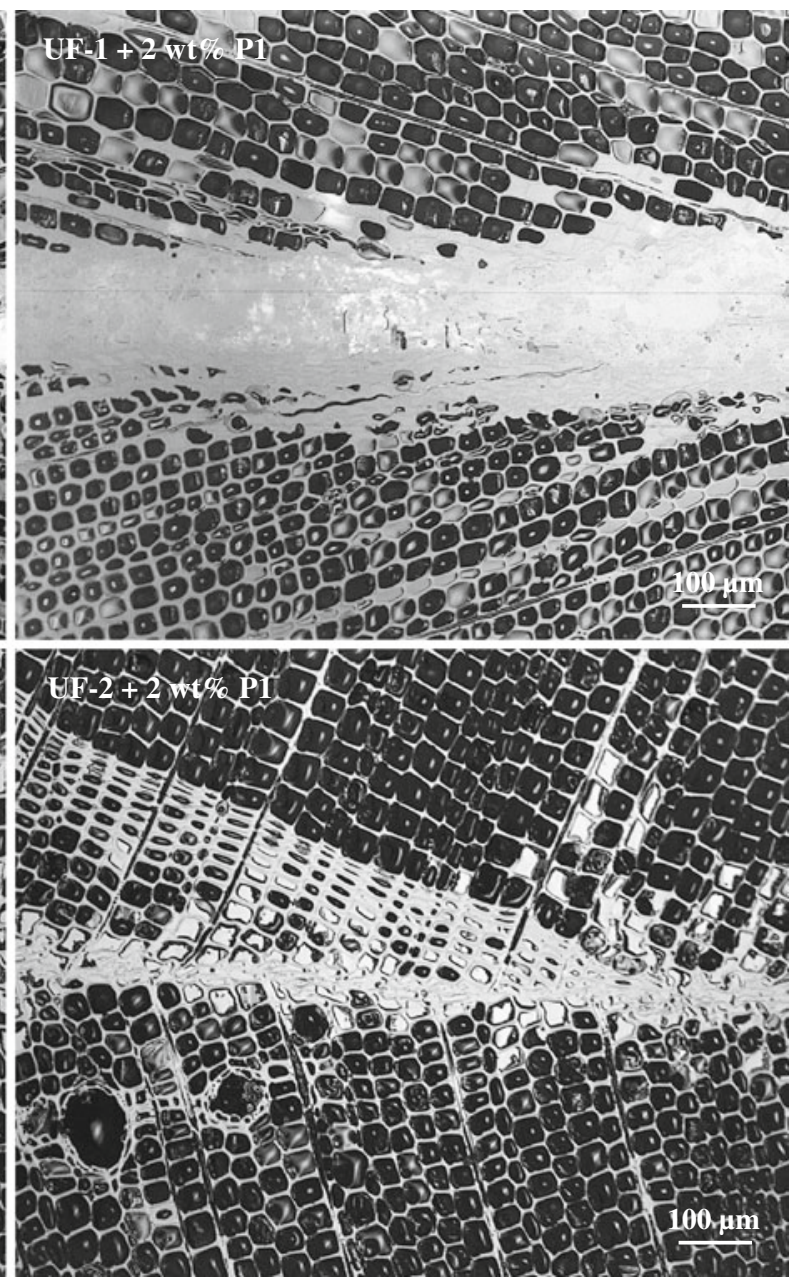

fibrillated pulp (P1). Adhesive spread was $250 \mathrm{~g} / \mathrm{m}^{2}$ of solid resin in all cases 


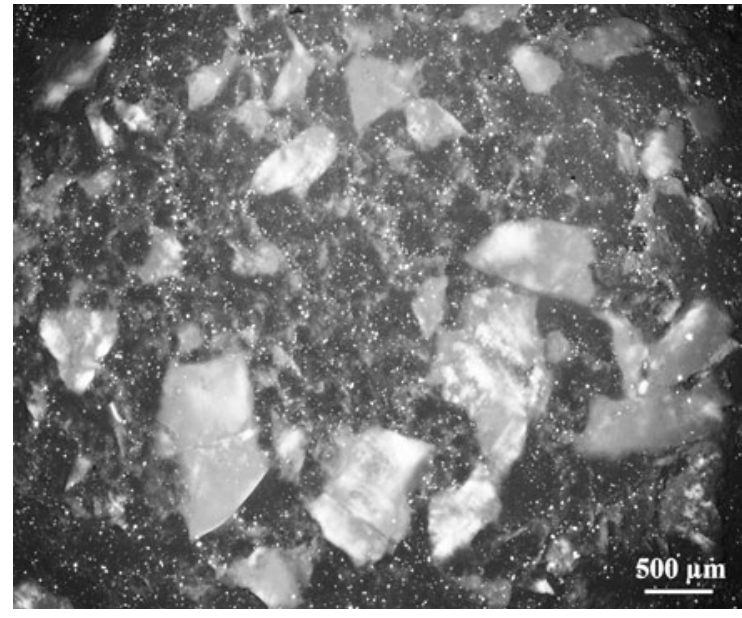

Fig. 5 Polarized light micrograph of liquid urea-formaldehyde- $(U F-2)$-adhesive filled with 2 wt $\%$ TEMPO-oxidized pulp ( $P 2)$. Large particles of $P 2$ remain after mixing with the adhesive. The small bright dots represent crystalline adhesive constituents

than for the pure adhesive, the increased viscosity of $\mathrm{UF}-2+\mathrm{P} 1$ might be responsible for that. It can be assumed that this is also true for UF-2 filled with P2 and $\mathrm{BC}$ since the bond line morphology was quite similar. Same as for UF-1, large particles of P2 remained within the adhesive after mixing by means of a hand held blender (Fig. 5).

Potential effects of CNF on the mechanical properties of the cured adhesive itself were studied by means of nanoindentation. The results of these experiments are summarized in Table 2. First of all, the two UF-resins used in the present study showed significantly different mechanical properties as UF-1 was clearly harder and stiffer than UF-2. The addition of $2 \mathrm{wt} \% \mathrm{CNF}$ resulted in a decrease in stiffness and hardness for UF-1, whereas a slight increase was observed for UF-2. However, these changes were not significant in a statistical sense ( $T$ test, $p \leq 0.05$ ). In addition to hardness and stiffness, the total work of indentation, the ratio between the elastic and plastic component of the work of indentation, and a creep factor were evaluated (Table 2). Particularly the ratio between the elastic and plastic component of the work of indentation is a good measure for the ductility of the adhesive. UF-2 turns out to be clearly more ductile than UF-1 and just as with hardness and stiffness, the ductility of adhesives as inferred from nanoindentation is not significantly affected by the addition of CNF. Considering the small percentage of cellulose added and the comparably high stiffness of UFsystems, a significant change in nanoindentation properties due to CNF addition, as observed for comparably soft hydroxypropyl cellulose (Zimmermann et al. 2005), would have been surprising. Thus, at least these results confirm that adhesive cure was apparently not affected in a negative manner by the addition of CNF, which is an important prerequisite for the further evaluation of macroscopic fracture experiments performed in the present study.

\section{Results of fracture energy testing}

The results of mode I fracture energy testing of adhesive bonds are summarized in Fig. 6. The specific fracture energy determined for unmodified UF showed very clear differences. With a value of $243.2 \pm 19.5 \mathrm{~J} / \mathrm{m}^{2} \mathrm{UF}-1$ yielded a result more than $200 \%$ the value of $111.2 \pm 27.8 \mathrm{~J} / \mathrm{m}^{2}$ for UF-2. The specific fracture energy of UF-1 is in a similar order as the specific fracture energy of a melamine-ureaformaldehyde adhesive used for constructive purposes characterized under identical conditions (Veigel et al. in press).

Table 2 Results of nanoindentation measurements performed on cured urea-formaldehyde-(UF) bond lines

\begin{tabular}{llllllr}
\hline Adhesive & $\begin{array}{l}\text { Number of } \\
\text { indents [1] }\end{array}$ & $\begin{array}{l}\text { Reduced modulus } \\
E_{r}[\mathrm{GPa}]\end{array}$ & $\begin{array}{l}\text { Hardness } \\
H[\mathrm{GPa}]\end{array}$ & $\begin{array}{l}\text { Total indentation } \\
\text { work } W_{\text {tot }}[\mathrm{pJ}]\end{array}$ & $\begin{array}{l}\text { Ratio } \\
W_{e} / W_{p}[1]\end{array}$ & $\begin{array}{l}\text { Indentation } \\
\text { creep } C_{I T}[1]\end{array}$ \\
\hline $\mathrm{UF}-1$ & 36 & $10.24 \pm 2.15$ & $0.63 \pm 0.11$ & $44.95 \pm 7.49$ & $1.24 \pm 0.32$ & $0.14 \pm 0.04$ \\
$\mathrm{UF}-1+2 \%$ P1 & 37 & $9.52 \pm 1.35$ & $0.59 \pm 0.11$ & $45.39 \pm 5.21$ & $1.25 \pm 0.24$ & $0.14 \pm 0.02$ \\
$\mathrm{UF}-2$ & 28 & $7.56 \pm 1.42$ & $0.40 \pm 0.09$ & $58.79 \pm 8.42$ & $0.77 \pm 0.11$ & $0.20 \pm 0.02$ \\
$\mathrm{UF}-2+2 \%$ P1 & 37 & $8.39 \pm 1.45$ & $0.42 \pm 0.03$ & $55.31 \pm 2.66$ & $0.79 \pm 0.11$ & $0.19 \pm 0.01$ \\
\hline
\end{tabular}

$W_{e} / W_{p}$ is the ratio of elastic to plastic deformation work, indentation creep $\left(C_{I T}\right)$ was defined as the relative change of the indentation depth while the applied load was kept constant. $U F-1, U F-2$ pure adhesives, $U F-1+2 \% P 1, U F-2+2 \% P 1$ adhesives filled with $2 \mathrm{wt} \%$ fibrillated beech pulp (P1) 


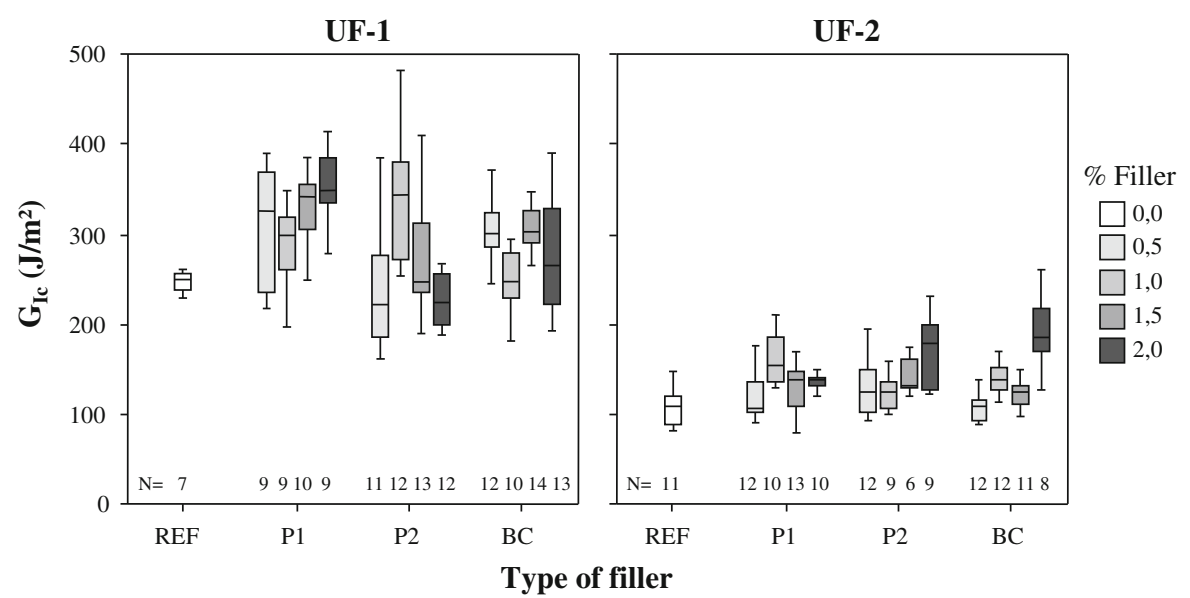

Fig. 6 Specific fracture energy $\left(G_{I c}\right)$ of adhesively bonded joints. Two urea-formaldehyde- $(U F)$-adhesives were applied without any additional filler $(R E F)$ and filled with cellulose nanofibrils from different sources $(P 1$ untreated pulp, $P 2$

The addition of CNF to UF exerted a number of significant effects on the specific fracture energy of adhesive bonds. Firstly, CNF-reinforced specimens showed higher variability than unmodified specimens on average, perhaps indicating sub-optimal dispersion of fibrils in several cases. Secondly, consistent improvements were only observed with UF-1, whereas significant increases of fracture energy were only sporadically found with UF-2, although a certain trend of improvement with CNF addition is apparent. As confirmed by visual observations during the preparation of the adhesive mixtures and microscopic investigations, large particles of $\mathrm{P} 2$ were present after mixing. For this type of cellulose the fibrils could definitely not be dispersed sufficiently well in order to achieve an optimum effect. Based on these observations it can be concluded that fibril dispersion was more efficiently done with UF-1, which comes as a powder, as compared to liquid UF-2.

A detailed analysis of results obtained for UF-1 reveals a clear trend of increasing toughness with increasing content of unmodified fibrils (P1). With a value of $353.0 \pm 43.2 \mathrm{~J} / \mathrm{m}^{2}$, which corresponds to an average increase of $45 \%$, UF-1 reinforced with $2 \%$ P1 showed the highest value of specific fracture energy for all tested groups of specimens. To statistically evaluate the effect of added filler, mean specific fracture energy values were compared by one-way ANOVA $(p \leq 0.05)$. The analysis revealed that four groups of specimens (UF-1 + P1 at a filler content of 1.5 and $2 \mathrm{wt} \%$ as well as UF-1 $+\mathrm{BC}$ at a
TEMPO-oxidized pulp, $B C$ bacterial cellulose). Boxplot symbols: broad line median, box 25-75\%-percentile, whiskers minimum and maximum value. The number of specimens tested for each group is given by $N$

content of 0.5 and $1.5 \mathrm{wt} \%$ ) showed significantly higher values than the unfilled UF-1 reference.

Regarding the three types of filler used in the present study it can therefore be said that it is possible to improve the specific fracture energy of UF-wood adhesive bonds by adding unmodified cellulose nanofibrils (P1) or fibrillated bacterial cellulose (BC), whereas this is not the case for TEMPOmodified cellulose fibrils (P2).

Having established the principal feasibility of improving UF-adhesive bond performance, the question of the cause for this improvement remains to be discussed. Since nanoindentation experiments did not reveal any significant effects of the addition of CNF on the bulk-polymer properties, it is proposed that the positive effect observed is caused by the role that CNF play in the process of crack formation during fracture. As outlined for carbon nanotube-toughened polymers (Mirjalili and Hubert 2010), a significant improvement of the fracture toughness of brittle polymers may be achieved due to fiber-bridging effects, given that the reinforcing fibers are of high tensile strength, above a certain critical length, and show sufficient interfacial adhesion to the polymer.

\section{Conclusions}

The results of the present study demonstrate the feasibility of toughening urea-formaldehyde wood 
adhesive bonds by adding cellulose nanofibrils. The combination of powder urea-formaldehyde with untreated cellulose nanofibrils proved best suitable for this purpose. An increase of the toughening effect up to $45 \%$ was observed when adding up to $2 \%$ cellulose nanofibrils. The fact that cellulose addition strongly increases the viscosity of the adhesive is a limiting factor to the amount of fibrils that can be added.

Acknowledgments The authors gratefully acknowledge financial support by the Austrian Science Fund (FWF) under grant P22516. Many thanks go to T. Zimmerman (EMPA) for taking the FE-SEM pictures and C. Tippelreither for his assistance in specimen preparation and mechanical testing.

\section{References}

Ahmad Z, Ansell MP, Smedley D (2010) Epoxy adhesives modified with nano- and micro-particles for in situ timber bonding: effect of microstructure on bond integrity. Int $\mathbf{J}$ Mech Mater Eng 5(1):59-67

Borysiak S, Garbarczyk J (2003) Applying the WAXS method to estimate the supermolecular structure of cellulose fibres after mercerisation. Fibres Text East Eur 11(5):104-106

Dunky M, Niemz P (2002) Holzwerkstoffe und Leime. Springer, Berlin

Eichhorn SJ, Dufresne A, Aranguren M, Marcovich NE, Capadona JR, Rowan SJ, Weder C, Thielemans W, Roman M, Renneckar S, Gindl W, Veigel S, Keckes J, Yano H, Abe K, Nogi M, Nakagaito AN, Mangalam A, Simonsen J, Benight AS, Bismarck A, Berglund LA, Peijs T (2009) Review: current international research into cellulose nanofibres and nanocomposites. J Mater Sci 45(1):1-33

Gagliano JM, Frazier CE (2001) Improvements in the fracture cleavage testing of adhesively-bonded wood. Wood Fiber Sci 33(3):377-385

Griffith AA (1920) The phenomena of rupture and flow in solids. Philos T R Soc S-A 221:163-198

Habenicht G (2002) Kleben-Grundlagen, Technologien, Anwendung. Springer, Berlin

Hsiao KT, Alms J, Advani SG (2003) Use of epoxy/multiwalled carbon nanotubes as adhesives to join graphite fibre reinforced polymer composites. Nanotechnology 14(7):791-793

Iwamoto S, Kai W, Isogai T, Saito T, Isogai A, Iwata T (2010) Comparison study of TEMPO-analogous compounds on oxidation efficiency of wood cellulose for preparation of cellulose nanofibrils. Polym Degrad Stabil 95(8):1394-1398

Khalili SMR, Shokuhfar A, Hoseini SD, Bidkhori M, Khalili S, Mittal RK (2008) Experimental study of the influence of adhesive reinforcement in lap joints for composite structures subjected to mechanical loads. Int $\mathbf{J}$ Adhes Adhes 28(8):436-444

Khalili SMR, Jafarkarimi MH, Abdollahi MA (2009) Creep analysis of fibre reinforced adhesives in single lap jointsExperimental study. Int J Adhes Adhes 29(6):656-661
Khoee S, Hassani N (2010) Adhesion strength improvement of epoxy resin reinforced with nanoelastomeric copolymer. Mat Sci Eng A Struct 527(24-25):6562-6567

Konnerth J, Jäger A, Eberhardsteiner J, Müller U, Gindl W (2006) Elastic properties of adhesive polymers. II. Polymer films and bond lines by means of nanoindentation. J Appl Polym Sci 102(2):1234-1239

López-Suevos F, Eyholzer C, Bordeanu N, Richter K (2010) DMA analysis and wood bonding of PVAc latex reinforced with cellulose nanofibrils. Cellulose 17(2):387-398

May M, Wang HM, Akid R (2010) Effects of the addition of inorganic nanoparticles on the adhesive strength of a hybrid solgel epoxy system. Int J Adhes Adhes 30(6): 505-512

Mirjalili V, Hubert P (2010) Modelling of the carbon nanotube bridging effect on the toughening of polymers and experimental verification. Compos Sci Technol 70(10): $1537-1543$

Nishino T, Takano K, Nakamae K (1995) Elastic modulus of the crystalline regions of cellulose polymorphs. J Polym Sci Pol Phys 33(11):1647-1651

Prolongo SG, Gude MR, Ureña A (2009) Synthesis and characterisation of epoxy resins reinforced with carbon nanotubes and nanofibers. J Nanosci Nanotechno 9(10): 6181-6187

Prolongo SG, Gude MR, Ureña A (2010) Rheological behaviour of nanoreinforced epoxy adhesives of low electrical resistivity for joining carbon fiber/epoxy laminates. J Adhes Sci Technol 24(6):1097-1112

Richter K, Bordeanu N, López-Suevos F, Zimmermann T (2009) Performance of cellulose nanofibrils in wood adhesives. In: Proceedings of the Swiss Bonding, Rapperswil, 239-246

Saito T, Nishiyama Y, Putaux JL, Vignon M, Isogai A (2006) Homogeneous suspensions of individualized microfibrils from TEMPO-catalyzed oxidation of native cellulose. Biomacromolecules 7(6):1687-1691

Saito T, Hirota M, Tamura N, Kimura S, Fukuzumi H, Heux L, Isogai A (2009) Individualization of nano-sized plant cellulose fibrils by direct surface carboxylation using TEMPO catalyst under neutral conditions. Biomacromolecules 10(7):1992-1996

Sakurada I, Nubushina Y, Ito T (1962) Experimental determination of the elastic modulus of crystalline regions in oriented polymers. J Polym Sci 57(165):651-660

Scherrer P (1918) Bestimmung der Größe und der inneren Struktur von Kolloidteilchen mittels Röntgenstrahlen. Nachr Ges Wiss Gött 2:98-100

Ureña A, Gude MR, Prolongo SG (2008) Carbon nanofibers reinforced adhesives for joining carbon fiber epoxy composites. In: Proceedings of the ECCM-13th European conference on composite materials

Veigel S, Follrich J, Gindl-Altmutter W, Müller U Comparison of fracture energy testing by means of double cantilever beam-(DCB)-specimens and lap joint testing method for the characterization of adhesively bonded wood. Eur $\mathrm{J}$ Wood Prod. In press. doi:10.1007/s00107-010-0499-6

Yoon SH, Kim BC, Lee KH, Lee DG (2010) Improvement of the adhesive fracture toughness of bonded aluminum joints using e-glass fibers at cryogenic temperature. J Adhes Sci Technol 24(2):429-444 
Zhang Y, You B, Huang H, Zhou S, Wu L, Sharma A (2008) Preparation of nanosilica reinforced waterborne silylated polyether adhesive with high shear strength. J Appl Polym Sci 109(4):2434-2441

Zimmermann T, Pöhler E, Geiger T (2004) Cellulose fibrils for polymer reinforcement. Adv Eng Mater 6(9):754-761
Zimmermann T, Pöhler E, Schwaller P (2005) Mechanical and morphological properties of cellulose fibril reinforced nanocomposites. Adv Eng Mater 7(12):1156-1161 